\title{
Information Specificity Vulnerability: Comparison of Medication Information Flows in Different Health Care Units
}

\author{
Eeva Aarnio ${ }^{1}$ and Reetta Raitoharju ${ }^{2}$ \\ 1 Turku School of Economics, Information Systems Science, \\ Rehtorinpellonkatu 3, Fl-20500 Turku, Finland \\ eeva.aarnio@tse.fi \\ 2 Turku School of Economics, Information Systems Science, \\ Rehtorinpellonkatu 3, FI-20500 Turku, Finland \\ reetta.raitoharju@tse.fi
}

\begin{abstract}
Information on patient's medication is often vital especially when patient's condition is critical. However, the information does not yet move freely between different health care units and organizations. Before reaching the point of putting into practice any system that makes the interorganizational medication information transmission possible, some prerequisites and characteristics of the information in different user organization should be defined. There are for instance units with different level of urgency and data/information intensity (e.g. emergency department vs. medical floor). The higher the urgency level, the more vulnerable the medication information flow is to different discontinuation situations. As a conceptual framework, a scoring system based on the asset specificity in the transaction cost theory and previous literacy on information flows of different health care units is created to define the vulnerability of the information flows. As there is a national medication database under planning, the scoring system could be used to assess the prerequisites for the medication database in Finland.
\end{abstract}

\section{Introduction}

The success of patient care is dependent on the availability of the appropriate information when needed. To be able to provide successful patient care it is essential to understand what effects technologies and work practices have on movement of information [1]. There are differences between the different health care units when it comes to the information needs [2] and the urgency to acquire the information. For

Please use the following format when citing this chapter:

Aarnio, I., Raitoharju, R., 2007, in IFIP International liederation for Information Processing, Volume 252, Integration and Innovation Orient to F-Socicty Volume 2, eds. Wang, W., (Boston: Springer), pp. 373-381. 
instance, the required information in an emergency department (ED) differs remarkably from the information required at a surgical-intensive care unit (SICU) [3].

The aim of using medications is to improve patients' health but sometimes there are also situations when medications cause injuries that could be preventable. The injuries could be caused for instance by the drug allergy of the patient, drug-drug interaction or wrong dosage. To prevent these errors, the patient data should be appropriately presented [4]. Without the appropriate movement of information between organizations, units and clinicians, the patient data including medication information could not be used to assure successful treatment of the patients. The movement of information is in this article called information flow. Reddy et al. [1, 229] use the term 'information flow' to describe patterns of information movement in a health care organization. According to them, the information flows are the ones that connect the different units of the hospital, but also units situated outside the hospital. In addition to the definition above, in this article the information flow also covers the flows inside the units.

Information could be bound to a particular site (e.g. incompatible computer system), time, person or knowledge and is therefore difficult or even impossible to move to another place and time [5]. The focus of this study is to explore the specificities present in different types of health care organizations and create a scoring system to define the most critical and vulnerable units in the context of medication information flow based on previous literature. Medication information is in this article defined as the generic and commercial name of the drug, the dosage, and the use indication.

The hospital districts in Finland are usually municipal federations consisting of one main hospital and several regional hospitals. In the same region, there are also various health centers owned by the municipalities and required by law to offer comprehensive primary health care services to the population of the municipality or other fixed area [6]. Almost all the health centers in Finland used an electronic patient record in 2006 but in the main and regional hospitals the electronic patient records were still in different implementation or development stages. There are many different electronic patient record systems in use but the national aim is to make it possible to move the patient information freely between different systems by the end of 2007. There are two possibilities for the extensive database: a centralized one, where all the organizations should have the same patient record system, and a decentralized base that is based on references which refer the place where the required information can be found. [7] However, the national database is still under planning and in the worst case it could take years before all the organizations could join in and use it efficiently [8]. Definition of the most vulnerable units is essential especially in the current situation of fragmented patient record systems and interfaces in Finland. The presented scoring system is based on the asset specificity in the transaction cost theory and previous literature on information flows of different health care units.

This paper is organized as follows: in the next section, information flows in the health care sector units are discussed. In chapter 3, specificities influencing health care sector units are presented based on previous research. Next, a conceptual framework for assessing the vulnerability of the medication information flow is 
provided. Finally, information flows in the context of medication information are discussed shortly.

\section{Special Characteristics of Health Care Units' Information Flows}

The information flow is dependent on the type of required information for instance in primary care [9]. As the required information varies, also the required information flow varies depending on the health care unit. The required information flow in each health care unit is different depending on for instance variables based on literature listed next, [e.g. 10]:

- Size of the clinic

- Purpose of the organization

- Depth of the physician-patient relationship

- Level of the specialization

Other variables affecting the flow are for example urgency of the operations performed at the unit, e.g. emergency department vs. surgical intensive care unit [3] and data intensity of the unit [e.g. 11]. The need for information technology solutions that guarantee the information to be available immediately is essential especially in the data-intensive, high-speed and heavily process-oriented areas such as emergency department (ED), the surgery area and the intensive care units (ICU) [11].

There are different types of intensive care units (ICU) (e.g. neonatal intensive care (NICU), surgical intensive care units (SICU)) and they all have in common the characteristic that all the possible medication-related risks should be minimized. The high intensity areas also differ from each other in data intensity. However, those areas are in any case a lot of more data-intensive than for instance medical/surgical floors in the inpatient hospitals [11]. In SICU or any intensive care units, the used medications are complex and extremely potent. The risks caused by medication errors are then also high. Information technology offers some possibilities to these situations. The requirements for the drug-related systems in the ICU are that they include patient-specific drug alerts, drug-drug interaction checking, recommended dosages and regime. Also the recognition of patients and drugs with a barcode are things that help in medication information use at the ICU. [12] In NICU the very tiny children are taken care of and even the smallest error can have significant impacts. Therefore patient's weight and age are especially essential information to have in the context of medication information. [13] Generally, surgery area is more dataintensive than ED or ICU. There is a lot of information needed and created during the surgery by many different people, e.g. anesthesiologist and nurses. [11].

In small offices or clinics there are usually paper-based patient record that are at hand easily [10]. Small organizations, such as small independent physician practices could, however, have problems related to finance and human resources when trying to acquire similar information technology than the big organizations [14]. Less technology is also required in less data intensive areas such as on a typical medical floor. For instance the vital signs of the patients on the floor do not need to be taken than once every hour to even eight hours whereas in the ICU the frequency could be even 5 or 10 minutes. Also the amount of clinicians is smaller on the floor [11]. 
The number of visits at the ED has multiplied and the complexity of the patients' illnesses has also increased. However, patients usually spend only a couple of hours at the ED [15]. The status of the patients is critical and they need to be treated as rapidly as possible. The ED is very information-intensive and collaborative in nature and the clinicians must find the accurate information fast, often from multiple resources. Patients' condition is often unknown when he/she is admitted to the ED and also the problems are not always clear. At the ED, the nursing staff usually has the best knowledge on patients' status and tasks performed, e.g. given medication. As in most of the units, one mistake can cause extreme consequences. When it comes to the medication given at the $\mathrm{ED}$, patient's weight, pain rating, symptoms, and the location of the pain should be known before deciding the medication. In the intensive settings there are often also information that is not written down, for instance, medication is given but it is not written down to the patient record. [3] Engeström [6] has studied the medical cognition. He has categorized the objects of medical cognition that are presented modified in the figure 1 .

\begin{tabular}{|c|c|c|}
\hline & $\begin{array}{l}\text { Domain is narrow and } \\
\text { well constrained, cases are } \\
\text { elective and foreseen } \\
\text { operations }\end{array}$ & $\begin{array}{l}\text { Domain is broad and } \\
\text { poorly constrained, cases } \\
\text { are unpredictable and/or at } \\
\text { some level urgent }\end{array}$ \\
\hline \multirow{2}{*}{$\begin{array}{l}\text { Cases are predominantly not } \\
\text { serious or demanding in } \\
\text { biomedical terms } \\
\text { Cases are predominantly } \\
\text { serious or demanding in } \\
\text { biomedical terms }\end{array}$} & $\begin{array}{l}\text { E.g., cosmetic } \\
\text { surgery }\end{array}$ & $\begin{array}{l}\text { E.g., primary care } \\
\text { general practice or } \\
\text { family practices }\end{array}$ \\
\hline & $\begin{array}{l}\text { E.g., oncology, } \\
\text { neurosurgery }\end{array}$ & $\begin{array}{l}\text { E.g., emergency room } \\
\text { medicine }\end{array}$ \\
\hline
\end{tabular}

Fig. 1. A two-dimensional classification of objects of medical cognition (modified from Engeström [6, 398]).

Analyzing the figure 1 in the context of medication information, in the upper left hand category there are tasks that are usually foreseen and there is plenty of time to acquire the information on the patients' condition and medication before the operation. In the upper right hand side there are tasks where the patient's medication information can be easily acquired before the appointment because the patient probably goes to the same place frequently with a wide range of problems that are not usually urgent. In the lower left hand category there are physicians' tasks that are serious medical problems for the patients and also need strong knowledge from the physician but because of the seriousness of the patient's condition, medication has probably been seriously considered and is well known at the time of the operation. The fourth category represents the situations where there are possibly serious cases and the range of them is wide. In the cases of this category, efficient information flows are mostly required because patient's life could be dependent on his/her medication information. 
As the data intensity is different in different units, also the systems that are ideal for each unit are different and many times there is a problem whether choose the ideal system or a system that compatible with other systems [11]. The focus of medical informatics (MI) research is to design IT applications that take into account the users (e.g. physicians, nurses, pharmacists). However, also only the change from the paper-based patient record has an effect on the communicative practices, the content and patterns of interdepartmental communication [14]. The paper records could be only viewed by one person at the time but with information systems many users can use it at the same time [15]. The individuals and institutions in healthcare settings familiarizing with new IT solutions are slow to change [16].

In Finland, only quite small number of patients moves from one organization to another. That is why the organizations should first fine-tune their own internal systems to match the expectations of the users [7]. For clinicians, the essential information on medication is the relevant patient history and data. To choose the right medication, they also require e.g. information on the dose forms, formulations and strengths the drug is available, appropriate clinical and dosage information. There could also be the information on which lab test results should be monitored or physical exams should be done. [13] The information flows in and between the units should provide this information taken into account the special characteristics of each unit.

\section{Specificities Influencing Health Care Sector Information Flows}

Asset specificity refers to the situation where assets are valuable in transactions between two certain partners. If the relationship between these two breaks, loss of value is caused by the break [17]. The concept of asset specificity is based on the transaction cost theory (TCT) that is an interdisciplinary approach joining economics, organization theory, and some aspects of contract law [18]. The different asset specificities classified by Williamson $[18,19]$ are human specificity, physical specificity, site specificity and dedicated assets. In the literature, also the specificities of time [20], procedural [21] and brand capital [e.g. 22] have been defined by different authors. Choudhury and Sampler [23] have studied the specificity of information and they add knowledge specificity in the list. In this article, the elaborated specificities are site, time, knowledge and human specificities. Human specificity is here understood as a specificity that refers to certain person possessing the asset and knowledge specificity refers to the specific knowledge of a professional. In noncommercial relationships transaction cost analysis cannot be realized completely but in those relationships there could be sacrifices of other valued objectives [18]. In this article, medication information is regarded as an asset. The costs could arise if the required medication information is not in the right time and place and, the patient cannot be treated correctly. The specificities could be seen consisting of hierarchically dependent layers so that the knowledge specificity is the strongest specificity, after that human, site and time specificities. In other words, if the information is knowledge specific, it is also human, site and time specific [5] 
Human specificity appears in the context of medication information for instance in a situation, when the patient him/herself, a nurse or a physician, is the only one that has the information on taken/given medication. It could be, that the context why something was done is not written down and it is only in the minds of the individuals involved [24]. Wireless technology is one of the factors influencing strongly in the information flows of the health care sector and could also be one solution for the human specificity. The technologies enable the real-time notification of patient-care events and release human resources, especially physicians from less-critical issues [1].

Site specificity is present for instance when paper-based data such as medication chart is used. It means that the information is located only in one place and could not be easily moved to another. The same situation could also be caused by the incompatibility of electronic patient record systems. The problem of time specificity, also known as temporal specificity, is present when information must be acquired very shortly after it becomes available or when it losses value if not used very soon after becoming available [23]. An example in the context of medication information is that patient's allergic reaction caused by a drug could be documented only at the moment it happens. Also a blood sample taken earlier could loose its value if patient's condition changes rapidly.

Knowledge specificity is present when special knowledge is required to acquire and/or interpret the information [23]. Patient him/herself cannot often interpret, why a certain prescription was written to him/her by the physician because special knowledge on the issue is required.

\section{Conceptual Framework for Analyzing the Information Flow in Different Health Care Units}

In table 1 the specificities and different types of health care units discussed in this article are presented. The characteristics that change between different units are for instance urgency of the cases, the broadness of the domain and information/data intensity. The scoring presented next is not based on any empirical data but on literature discussed earlier. The more there are points (max. 4) the more vulnerable the flow of medication information and the more essential it is to treat the patient rapidly, and the more problems are caused if the information flow breaks down.

Table 1. Information flows and different health care units' information specificity vulnerability.

\begin{tabular}{lccccc}
\hline Type of Unit & $\begin{array}{c}\text { Site } \\
\text { Specificity }\end{array}$ & $\begin{array}{c}\text { Time } \\
\text { Specificity }\end{array}$ & $\begin{array}{c}\text { Knowledge } \\
\text { Specificity }\end{array}$ & $\begin{array}{c}\text { Human } \\
\text { Specificity }\end{array}$ & Score \\
\hline ED & $\mathbf{x}$ & $\mathbf{x}$ & $\mathbf{x}$ & $\mathbf{x}$ & 4 \\
ICU & $\mathbf{x}$ & $\mathbf{x}$ & $\mathbf{x}$ & - & 3 \\
Medical Floor & $\mathbf{x}$ & - & - & - & 1 \\
Primary Care & $\mathrm{x}$ & - & - & - & 1 \\
Small Clinic & $\mathrm{x}$ & - & $\mathrm{x}$ & - & 2 \\
\hline
\end{tabular}


In the "high score" units like ED the medication information flow is affected easily and extreme problems are caused if the flow breaks down because of any specificity, for instance, a patient in critical condition is brought at the ED but his/her medication information is only in a paper-based patient record in some other unit (site specificity) or worse, he/she is the only one to tell the real medication (human specificity). The information should be acquired as soon as possible because of the critical condition (time specificity). Still, even if the medication information is acquired in the right place in the right time, a physician is required to interpret, what are the possible effects etc. the medication could cause during the treatment (knowledge specificity). In the primary care and medical floor units the knowledge is of course also required but the need for human resources, e.g. physicians or the treatment in general may not be that time specific than in the ED or ICU. At a small clinic the cases may not be that time specific either but the criticality is based on the fact that there could be only one physician at the clinic and without him/her the clinic cannot operate. The human specificity is present mostly in the ED because the patient may not be able to tell his/her medication information but in other units the patient is in the condition to tell the information or the information has been acquired earlier (e.g. medical floor or ICU). However, the table presents only the requiring side of the information flow. Small clinics, primary care or suchlike may not usually need medication information rapidly but are remarkable producers of the information. Therefore in a critical situation it should be essential that also above mentioned units could provide the medication information prescribed for the patient in their unit.

\section{Discussion}

After discussing the specificity vulnerability of the medication information flows, it should be assessed, how to guarantee the efficient flows between the units producing medication information and the units requiring the information in critical and less critical moments. In the case of Finnish medication data base solution, there should be considerations on how to integrate also the small, perhaps private organizations to the medication database at affordable price. The question to be asked is, would it be more secure that the units had their own medication records and the other units collected the required information based on the references, or that there was one national database where all the units should join in one way or another. The critical factors here are how to answer efficiently the requirements of urgency and data intensity of each unit and guarantee the information flow without any shortages. If there is only a small amount of patients moving from one organization to another [7] and if in most cases time is the critical factor in treating the patient, would it then be safer to have the decentralized databases if it was possible to read the information by using some references? Or, would one national medication database be the right choice to share the information? Further research should then focus on studying the risks of shortages related to the one national database compared to the amount of medication information required from other organizations' databases. If the need for information is minor than the risk of breaking the information flow completely, it 
should be carefully weighted, how to put into practice this process of getting rid of the fragmented medication information in Finland.

\section{References}

1. M.C. Reddy, et al., Technology, work, and information flows: Lessons from the implementation of a wireless alert pager system. Journal of Biomedical Informatics.38(3),229-238 (2005)

2. R.N. Jerome, et al., Information needs of clinical teams: analysis of questions received by the Clinical Informatics Consult Service. Bulletin of the Medical Library Association.89(2),177-185 (2001)

3. M.C. Reddy and P.R. Spence, Collaborative information seeking: A field study of a multidisciplinary patient care team Information Processing and Management.Article in press (2007)

4. G.J. Kuperman, et al., Medication-related Clinical Decision Support in Computerized Provider Order Entry Systems: A Review. Journal of the American Medical Informatics Association.14(1),29-40 (2007)

5. E. Aarnio and R. Raitoharju. Information specificity in the context of medication information: a conceptual analysis. in The 30th Information Systems Research Seminar in Scandinavia IRIS 2007. 2007. Tampere, Finland.

6. Y. Engeström, Objects, contradictions and collaboration in medical cognition: an activity-theoretical perspective. Artificial Intelligence in Medicine.7(5),395-412 (1995)

7. K. Mäkelä, Terveydenhuollon tietotekniikka - Terveyden ja hyvinvoinnin sovellukset. 2006, Helsinki: Talentum.

8. J. Lahti, Potilastietoa uhkaa vuosien tietokatkokset. 2007: Digitoday, www.digittoday.fi.

9. N. Blackburn, Building bridges: towards integrated library and information services for mental health and social care. Health Information and Libraries Journal.18(4),203-212 (2001)

10. P.N. Gorman, Information Needs of Physicians. Journal of the American Society for Information Science.46(10),729-736 (1995)

11. M. Hagland, Intensive Care: The Next Level for IT. Health Management Technology.19(13) (1998)

12. M. Kaukonen, Lääkitysvirheet tehohoidossa. Finnanest.39(1),36-38 (2006)

13. K. Lillis, Automated Dosing. Health Management Technology.24(11),36-37 (2003)

14. M. Chiasson, et al., Expanding multi-disciplinary approaches to healthcare information technologies: What does information systems offer medical informatics? International Journal of Medical Informatics. Corrected proof (2006)

15. Anonymous, ED on Track With IT. Health Management Technology.26(8),28-31 (2005)

16. P.A. Gross and D.W. Bates, A Pragmatic Approach to Implementing Best Practices for Clinical Decision Support Systems in Computerized Provider Order 
Entry Systems. Journal of the American Medical Informatics Assaciation.14(1),2528 (2007)

17. P.-O. Bjuggren, Competition for the Market in the Swedish Primary Health Care Sector. International Review of Law and Economics.18(4),529-541 (1998)

18. O. Williamson, The Economics of Organization: The Transaction Cost Approach. American Journal of Sociology.87(3),548-577 (1981)

19. O. Williamson, The Economic Institutions of Capitalism. 1985, New York: Free Press.

20. T.W. Malone, J. Yates, and R.I. Benjamin, Electronic markets and electronic hierarchies. Communications of the ACM.30(6),484-497 (1987)

21. A. Zaheer and N. Venkatraman, Determinants of Electronic Integration in the Insurance Industry: An Empirical Test. Management Science.40(5),549-566 (1994)

22. D. Lamminmaki, Why do hotels outsource? An investigation using asset specificity. International Journal of Contemporary Hospitality Management.17(6),516-528 (2005)

23. V. Choudhury and J.L. Sampler, Information Specificity and Environmental Scanning: An Economic Perspective. MIS Quaterly, (March 1997) (1997)

24. M.C. Reddy, et al. Asking Questions: Information Needs in a Surgical Intensive Care Unit. in Proceedings of the American Medical Informatics Association Fall Symposiun AMIA'02. 2002. San Antonio, TX. 